OPEN ACCESS

Edited by:

Jerker Rönnberg,

Linköping University, Sweden

Reviewed by:

Sascha Schwarz,

University of Wuppertal, Germany

Björn Lyxell,

Linköping University, Sweden

*Correspondence:

Benjamin P. Lange

benjamin.lange@uni-wuerzburg.de

Specialty section

This article was submitted to

Language Sciences,

a section of the journal

Frontiers in Communication

Received: 24 April 2018 Accepted: 22 January 2019

Published: 12 February 2019

Citation:

Lange BP, von Andrian-Werburg MTP, Adler DC and Zaretsky E (2019) The

Name Is the Game: Nicknames as

Predictors of Personality and Mating

Strategy in Online Dating.

Front. Commun. 4:3.

doi: 10.3389/fcomm.2019.00003

\section{The Name Is the Game: Nicknames as Predictors of Personality and Mating Strategy in Online Dating}

\author{
Benjamin P. Lange ${ }^{1 *}$, Maximilian T. P. von Andrian-Werburg ${ }^{1}$, Dorothea C. Adler ${ }^{1}$ and \\ Eugen Zaretsky ${ }^{2}$
}

${ }^{1}$ Department of Media Psychology, Faculty of Human Sciences, Institute Human-Computer-Media, Julius Maximilian University of Wuerzburg, Würzburg, Germany, ${ }^{2}$ Department of Phoniatrics and Pediatric Audiology, University of Marburg, Marburg, Germany

Objective: We investigated the communicative function of online dating nicknames. Our aim was to assess if it is possible to correctly guess personality traits of a user simply by reading his/her nickname.

Method: We had 69 nickname users (average age: 33.59 years, 36 female) complete questionnaires assessing their personality (Big $5+$ narcissism) and mating strategy (short- vs. long-term). We then checked (using a total of 638 participants, average age: 26.83 years, 355 female), whether personality and mating strategy of the nickname users could be assessed correctly based only on the nickname. We also captured the motivation to contact the user behind a nickname and looked at linguistic features of the nicknames.

Results: We found that personality and mating strategy could be inferred from a nickname. Furthermore, going by trends, women were better at intersexual personality judgments, whereas men were better in intrasexual judgements. We also found several correlates of the motivation to contact the person behind the nickname. Among other factors, long nicknames seemed to deter people from contacting the nickname user.

Conclusions: Findings display that humans are capable of making accurate personality judgements in computer-mediated communication by means of even small cues like nicknames.

\section{Keywords: computer-mediated communication, hyperpersonal communication, linguistic cues, nicknames, online} dating, personality judgments

\section{INTRODUCTION}

Language-based face-to-face (ftf) interaction can be considered the most natural way of communication (Kock, 2004). New social media have transformed communication, though, as sender and receiver are not necessarily copresent in such a mediated context. However, communication in the digital world is still language-based, even when only in the form of written language (Koch et al., 2005).

Research on such computer-mediated communication $(\mathrm{cmc})$ can be divided into different approaches. Two of them are: (1) the reduced-social-cues approach (rsc) (Sproull and Kiesler, 1986), and (2) the hyperpersonal communication approach (hp) (Walther, 1996). The first assumes that $\mathrm{cmc}$ filters out social context cues. The second emphasizes that $\mathrm{cmc}$ might surpass $\mathrm{ftf}$ communication, as the sender has the opportunity to optimize their self-representation while the 
receiver idealizes the sender on the basis of the available cues. Here lies the question whether people are able to, and actually do hide their "true selves", that is their identity (e.g., personality), or whether they, despite being relatively anonymous, inevitably communicate aspects of their respective identity and personality that are in turn perceived by the receiver (Walther and Parks, 2002).

Sex or gender, respectively, are central features of one's identity and personality (e.g., Mealey, 2000; Ellis et al., 2008). As a matter of fact, sex has been central in $\mathrm{cmc}$ research. For instance, Guiller and Durndell (2007) found that in cmc men are more dominant than women, whereas women are more supportive than menfindings reminiscent of sex differences in $\mathrm{ftf}$ communication (Eckert and McConnell-Ginet, 2003).

A large body of research (e.g., Savicki et al., 1999; Thomson and Murachver, 2001; Koch et al., 2005) shows that only by reading text, people are able to guess the sex of the writers above chance. The same seems to be true for personality judgments (Park et al., 2015). Entire texts are not necessary, though. Lange et al. (2016b) used pseudonyms chosen by students in written exams, and had participants rate them on assumed sex of the user and other attributes. They found that sex could be guessed correctly above chance with a large effect size. Also, participants ascribed typical female and male attributes to the pseudonyms and even tried to retrieve information on the users' personality. It was also found that women, more than men, used diminutive suffixes in their pseudonyms (like $-i$ in "cuti"). In line with these findings, Heisler and Crabill (2006) demonstrated that the majority of their participants considered themselves capable of correctly guessing the sex and age of the users of e-mail usernames. Moreover, their participants attempted to rate the supposed owners of the e-mail addresses also with respect to, among other aspects, their relationship status.

Not only is sex a matter of interest with respect to the digital world, the phenomenon of online dating is, too (Valkenburg and Peter, 2007). Considering that mate choice is one of the most important areas in social life (Buss, 2003) and that people are increasingly shifting their activities from the offline to the online world, it does not surprise that online dating has become a billion-dollar business (Sautter et al., 2010).

Human mating in general and sex differences in human mating have attracted numerous researchers and have produced a veritable deluge of related literature (e.g., Buss and Barnes, 1986; Buss, 1989; Buss and Schmitt, 1993; for an overview, see Buss, 2003, 2016; Schwarz and Hassebrauck, 2012). This research has, on the one hand, identified several characteristics that both sexes prefer in a mate (e.g., healthy), as well as those that are more preferred by women (e.g., good earning capacity, college graduate) and those more preferred by men (e.g., physically attractive) (Buss et al., 1990). The role of language in human mate choice has also been examined recently (e.g., Lange et al., 2014, 2016a). On the other hand, empirical mate choice research has documented that women are more exacting in mate choice decisions, while men face stronger same-sex competition (for an overview, see Buss, 2003). The first process, called intersexual selection, is the actual mate choice, which in most species occurs as female mate choice. That is, women because of having higher obligatory costs (Trivers, 1972), are more selective, while men, whose obligatory costs are lower, compete more strongly with other men in order to be chosen. This is called intrasexual selection (for an overview, see Buss, 2003).

Another area of interest in mate choice research is the distinction between short-term mating (the search for an affair, a one-night stand, etc.) and long-term mating (the search for a committed, steady relationship) (Buss and Schmitt, 1993), which can be referred to as a person's mating strategy (Schmitt, 2005). This distinction is somewhat linked to females being choosier than males. As the costs for males are lower than for females, men show a tendency to be relatively indiscriminate in shortterm mating. A bad mate choice imposes higher costs on women than on men-and this applies more to short-term than to longterm mating. Generally, women show a preference for a longterm mate (Buss and Schmitt, 1993). As a result, men for whom short-term mating is a particularly useful strategy might want to pretend to be interested in long-term mating, while in fact they are not. Thus, women should be particularly interested in detecting a man's mating strategy (Buss, 2003).

Not only dating in general but online dating as well has excited some research interest-among others, also with respect to rsc and hp (for an overview, see Finkel et al., 2012). It has been assumed, taking the hp perspective, that the $\mathrm{cmc}$ limitations in online dating can be compensated by language style and choice of words (Walther et al., 2005). While physical cues are missing in $\mathrm{cmc}$, the importance of verbal cues might be rising. The question then might very well be, this time with respect to online dating: what about single words instead of entire texts?

As emphasized above, communication only by means of single words is even more limited than communicating through written texts. Still, those single words might communicate crucial information (Lange et al., 2016a). In accordance with findings on mate choice in "real life," Whitty and Buchanan (2010) found that women were more attracted to online user names (hereinafter called nicknames) (e.g., in terms of the motivation to contact the person behind the name) that signaled intelligence, while men were more attracted to nicknames indicative of physical attractiveness. So the choice of a nickname in online dating can be used for impression management-just like hp would predict. Online dating is indeed an area in the digital world in which making a good first impression is essential (Whitty and Buchanan, 2010).

Apart from classical mate choice criteria, the personality of a potential mate is crucial, too (e.g., Buss et al., 1990; Botwin et al., 1997; Escorial and Martín-Buro, 2012). In this context, research by Back et al. (2008) is particularly relevant for the research presented in the article at hand. They retrieved personality scores of 599 participants (Big Five, e.g., extraversion; narcissism) and additionally asked them for their e-mail addresses. Back et al. (2008) then presented the e-mail names to 100 participants who judged the personality dimensions of the e-mail name users on the same personality items used before. Personality dimensions were detected correctly, with results being statistically significant for all dimensions except for extraversion. Back et al. (2008) also showed that personality ratings were linked to certain attributes of the e-mail address. For instance, the perception of 
conscientiousness was positively correlated with both the number of characters and dots the names consisted of, while number of digits was negatively correlated with it.

The current study had the objective of replicating the findings by Back et al. (2008) with respect to online dating as well as to extend them. Back et al. (2008) used e-mail names and had a general $\mathrm{cmc}$ context. We, on our part, wanted to focus more on nicknames. This was inspired by research on the psychology of pseudonyms (e.g., Lange et al., 2016b) as well as based on the following assumption: While e-mail addresses are often created based on the rule "first name.last name" (e.g., john.smith@...), nicknames are assumed to be more creative (cf. Whitty and Buchanan, 2010). Also unlike Back et al. (2008), we were interested in the context of online dating and mate choice. Whitty and Buchanan (2010) have already shown that such an approach is worthwhile. Still, the scarcity of such research calls for more studies of this kind.

The question might also be asked, as to whether people are able to detect the mating strategy of a potential mate. It was also of interest whether the motivations for contacting a person behind a nickname, based only on the nickname, might differ (Whitty and Buchanan, 2010). Furthermore, we wanted additionally to investigate whether one of the two sexes are better at judging women's and men's personality based on their nicknames. Mating is an area of social life, where making a proper choice seems particularly important (Buss, 2003). So, it seemed of practical relevance to elucidate what mate choice-relevant information can be retrieved form an online dating nickname.

Finally, we were interested in the linguistic features of the nicknames, and the subsequent question whether we would find correlations between these features and other variables of interest (Back et al., 2008; Lange et al., 2016b).

We proposed the following hypothesis (cf. Back et al., 2008):

H1: People are able to correctly guess online daters' personality by means only of their nicknames. Under personality, we understood the Big Five dimensions which are: openness to experience, conscientiousness, extraversion, agreeableness, and neuroticism (McCrae and John, 1992). The Big Five have been used quite often in research focusing on personality perceptions by means of certain cues (e.g., Küfner et al., 2010; Qui et al., 2015). As another personality dimensions, we added narcissism following the mentioned study by Back et al. (2008). Other researchers have also included this trait, which is one of three traits of the so-called Dark Triad, into their research in order to elucidate, whether it can be detected (e.g., Buffardi and Campbell, 2008; Vander Molen et al., 2018).

Furthermore, we had four research questions that were derived from mate choice research (see above) and other studies on the psychology of nicknames or usernames (Back et al., 2008; Whitty and Buchanan, 2010; Lange et al., 2016b):

RQ1: Are people able to correctly guess online daters' mating strategy by means only of their nicknames?

RQ2: What are the correlates of the motivation to contact a person behind a nickname?
RQ3: Does one sex show greater accuracy in personality judgments than the other?

RQ4: What are the linguistic correlates of the personality of the nickname users and how are they perceived? In other words, are linguistic features significant mediators of judgments?

\section{METHODS}

We conducted a two-step study consisting of four independent online surveys in Germany. In the first step we assessed the personality dimensions of nickname users (sample 1). They also gave standard demographical information and indicated their mating strategy. In the second step, participants rated the nickname users based on the nicknames only. First, participants (sample 2) rated the assessed personality dimensions of step 1 (H1 \& RQ3). Further samples of participants (sample 3) rated the nickname users' mating strategy (RQ1) and rated how motivated they would be to contact the nickname users (sample 4) (RQ2). Finally, the nicknames retrieved in step 1 were analyzed linguistically or, to be more precise, morphologically (i.e., with respect to their form) (RQ4) in order to use the values so retrieved in correlational and mediational analyses.

The research reported in our manuscript meets the ethical guidelines of the German Society of Psychology (Deutsche Gesellschaft für Psychologie, DGPs) and is consistent with the principles of research ethics as published by the American Psychological Association (APA). Data collection was completely anonymous. That is, except for standard information (e.g., age and gender), we did not record personal information from the participants. All participants in the studies were clearly instructed that they would give their consent by virtue of survey completion. The research reported here had not been approved by a local ethics committee because the ethical guidelines of the German Society of Psychology do not require ethical approval of basic psychological studies involving simple behavioral data.

\section{Measures}

In both steps we used a German ten-item short version (BFI-10) of the Big Five Inventory (BFI-44) (Rammstedt and John, 2007). This well-known and established instrument shows sufficient psychometric properties (Rammstedt and John, 2007). Each Big Five dimension was rated through two items on a 5-point scale $(1=$ "disagree strongly" to $5=$ "agree strongly"). The Big Five dimensions were: Openness to experience, Conscientiousness, Extraversion, Agreeableness, and Neuroticism (McCrae and John, 1992). Narcissism was assessed with three items on a 9point scale taken from the German dark triad short scale (Küfner et al., 2015). Nickname users were asked to indicate their mating strategy on a 5 -point scale ( $1=$ "short-term" to $5=$ "long-term"). For step 2, the items assessing personality and mating strategy were reformulated from first to third person.

Participants from step 2 (RQ2, sample 4) rated the nicknames on the following item: "How motivated would you be to contact someone with each of the following nicknames?" on a 5-pointscale ( 1 = "extremely unmotivated" to $5=$ "extremely motivated"; cf. Whitty and Buchanan, 2010). We asked participants in both 
steps about their age, sex/gender, sexual orientation and level of education.

\section{Participants and Procedure: First Step}

Online daters at the dating website finya.de were contacted and their participation solicited using standardized private text messages that included a link to the step 1 questionnaire. We posted the link also on Facebook in order to enlist additional participants. Inclusion criteria here were that the potential participants were dating online and were using a nickname while online dating. Exclusion criterion for step 1 was homosexual orientation. This was done because of our focus on mate choice research that has, due to a high prevalence of heterosexuality, mainly investigated heterosexual mate choice (see Buss, 2003). Also, research has shown that both the preferred mate choice criteria as well as the actual mate choice of heterosexual people differ from homosexual people (e.g., Gobrogge et al., 2007).

The final sample 1 contained 69 non-homosexual participants (68 heterosexual, 1 bisexual; 36 female, 33 male) with an average age of 33.59 years $(S D=10.08)$. The majority of these participants were educated below a college degree $(n=39)$. Answering the item asking for the pursued mating strategy was voluntary. Seven participants (all female) refused to answer this item, thus resulting in $n=62$ for this item.

\section{Participants and Procedure: Second Step}

In our second step we used reformulated items from step 1 for the questionnaire. For all ratings in step 2, 5-point rating scales were used in order to make the questionnaires consistent for our participants in this respect.

For sample 2, we decided, in order to not fatigue our participants, to present a randomly drawn sample of 10 nicknames below each item instead of all 69 nicknames. Our target was 60 ratings per nickname on each item with a balanced sex ratio. This led to a planned sample size of 414 participants. Our final sample 2 (H1 \& RQ3) consisted of 414 participants (227 female, 180 male, 7 unknown) with an average age of 27.11 years $(S D=9.33)$. On average, each nickname was thus rated on every item by approx. 60 participants $\left(M=59.44 ; M_{f \text { emale }}=32.56\right.$, $\left.M_{\text {male }}=26.88\right)$. Most participants were heterosexual $(n=349$, $84.3 \%$ ) followed by participants who refused to answer $(n=26$, $6.3 \%)$ and bisexual participants $(n=25,6.0 \%)$. Fourteen participants reported a homosexual orientation (3.4\%). For the analyses referring to RQs 1-3, those homosexual participants were excluded due to the reason elaborated on above. The nonhomosexual sample consisted of 394 participants (222 female, 172 male) with an average age of 26.91 years $(S D=9.33)$.

In order to investigate whether people would be able to detect the mating strategy of a nickname user (RQ1), an additional sample (sample 3) of 94 non-homosexual participants (63 female, 31 male) with an average age of 26.19 years $(S D=6.18)$ rated the 62 nicknames (see above). As we were also interested in people's contact motivation as a function of nickname (RQ2), we recruited another sample (sample 4) of a total of 130 participants (65 female, 65 males) with an average age of 26.41 years $(S D=7.67)$. Ratings (RQs 1 \& 2) were done by opposite-sex participants due to the reason elaborated on above.
For RQ4, we looked at different parameters of pseudonym length (cf. Lange et al., 2016b, for a similar procedure): number of words, number of syllables, and number of characters (counted by first author of the article at hand), as well as number of morphemes (with and without digits; counted by senior author, a trained linguist). Following the procedure by Back et al. (2008), we also counted dots, hyphens, and underscores. These attributes, however, were extremely rare in our sample ( $M$ s between 0.03 and 0.14 ) and were thus not considered in our analyses.

\section{Statistical Analyses}

The analyses for H1 and RQs 1-3 were performed by means of correlational analyses (Pearson's $r$ ). The analyses for RQ4 included correlational analyses as well as mediational analyses using the PROCESS macro for SPSS Statistics. Following the recommendations by Hayes (2013), bootstrapping analyses were performed for investigating the mediations. Here, we used $m=50,000$ bootstrap samples for bias corrected bootstrap confidence intervals. Also, $t$-tests and chi-square tests were performed for RQ4.

In the results section, significance values are reported onetailed for $\mathrm{H} 1$ and two-tailed for RQs 1-4, if not stated otherwise. As parts of our research were exploratory (e.g., RQs 1 \& 3), we decided against adjustment of significance values in order to make sure not to miss important results (Rothman, 1990; Perneger, 1998). Following Back et al. (2008), we used the following significance levels: $p<0.10$ (marginally significant), $p<0.05, p<0.01$, and $p<0.001$. Still, as our sample size was only 69 , we will focus on effect sizes rather than on statistical significance. For all statistical analyses, the nicknames and their users were used as cases in SPSS.

\section{RESULTS}

\section{H1: People Are Able to Correctly Judge Online Daters' Personality}

Using the entire sample of nicknames and all raters, it was found that openness $\left[r_{(67)}=0.248, p=0.020\right]$, conscientiousness $\left[r_{(67)}=0.179, p=0.071\right]$, extraversion $\left[r_{(67)}=0.332, p=0.003\right]$, agreeableness $\left[r_{(67)}=0.166, p=0.087\right]$, and narcissism $\left[r_{(67)}=0.160, p=0.095\right]$ were correctly detected above chance. Only neuroticism $\left[r_{(67)}=0.089, p=0.233\right]$ was not significantly judged correctly. In sum, H1 was thus mostly supported. Mean correlation in our data was $r=0.196$ and thus more than twice as high as the mean correlation $(r=0.092)$ in the study by Back et al. (2008). This difference between the two studies, however, is not significant ( $z=0.82, p=0.412$, two-tailed).

Figure 1 gives a visual summary of the findings with respect to H1. Table 1 shows all obtained intercorrelations between selfreported and judged personality, self-reported and judged mating strategy, contact motivation, and the linguistic length parameters.

Openness and extraversion were the two personality dimensions that were judged correctly with the highest accuracy (see Figure 1). We found several correlations between nickname length and the nickname users' personality (see Table 1). For instance, the longer the nicknames in terms of morphemes, the less open [with/without digits: $r_{(67)}=-0.245 /-0.149$, 


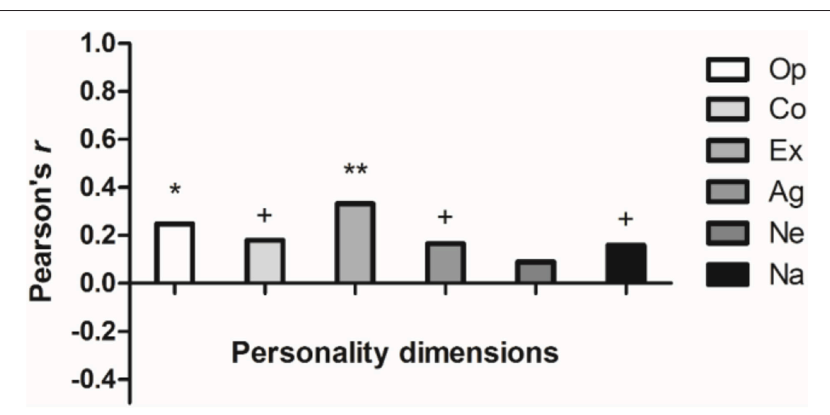

FIGURE 1 | Correlation coefficients between nickname users' self-reported personality dimensions and participants' personality judgments based on nicknames. Op, Openness to experience; Co, Conscientiousness; Ex, Extraversion; Ag, Agreeableness; Ne, Neuroticism; Na, Narcissism. $+p<0.10,{ }^{*} p<0.05,{ }^{* *} p<0.01$.

ps $=0.042 / 0.222$, two-tailed] were their users. Also, the number of characters was negatively correlated with openness $\left[r_{(67)}=-0.214, p=0.078\right.$, two-tailed]. So, nickname length could be a simple cue for estimating the personality of the nickname user (RQ4). Hence, we conducted mediational analyses. The self-reported personality score (for openness or extraversion) entered the analysis as predictor, judged personality score as outcome variable and the length parameters as mediators. It was found that number of morphemes with digits was a significant mediator $\left(b_{\text {indirect }}=0.036,95 \% \mathrm{CI}_{\mathrm{BC}}\right.$ $[0.003,0.103], m=50,000)$ between self-reported and judged openness. That means the number of morphemes was used as a cue for correct openness judgments. The direct effect $\left(b_{\text {direct }}=0.070,95 \% \mathrm{CI}_{\mathrm{BC}}[-0.039,0.179], m=50,000\right)$ was not significant anymore $(p=0.202$; cf. Table 1$)$. Hence, the correlation between self-reported and judged openness can be explained by number of morphemes. It is noteworthy that the correlation between both self-reported and judged openness and number of morphemes was negative (see Table 1). This means that nickname shortness can be used as a cue for the nickname user's openness. For extraversion, no significant mediation was found.

\section{RQ1: Mating Strategy}

We found a mean rating of $M=4.11(S D=0.98)$ on the 5-point rating scale. There was thus a highly significant tendency toward the pursuit of a long-term mating strategy in our sample $\left[t_{(61)}=8.971, p<0.001, d=1.13\right]$. As to sex differences, it was found that women were a little stronger in pursuing a long-term strategy $(M=4.28, S D=0.96)$ than men $\left[M=3.97, S D=0.98 ; t_{(60)}=1.237, p=0.221, d=0.32\right]$. This difference was not significant, but yielded at least a small effect size.

More importantly, our participants were able to guess the users' mating strategy $\left[r_{(60)}=0.346, p=0.006\right]$. This was only evident for female nicknames judged by men $\left[r_{(27)}=0.464, p=0.011\right]$. Hence, men could detect women's mating strategy based on their nicknames, while women were not as good at detecting men's mating strategy $\left[r_{(31)}=0.272\right.$, $p=0.125]$.
Furthermore, (see Table 1), people seeking a short-term relationship used longer nicknames (RQ4). So, we investigated, whether the length parameters were cues that were used for correct mating strategy judgments. No significant mediation was found. Indeed, no length parameter correlated with rated mating strategy (see Table 1). Hence, there might be linguisticmorphological cues to one's mating strategy that are not perceived as such.

\section{RQ2: Contact Motivation}

The more conscientious $\left[r_{(31)}=0.388, p=0.026\right]$ men were and the less they were both neurotic $\left[r_{(31)}=-0.321, p=0.068\right]$ and narcissistic $\left[r_{(31)}=-0.432, p=0.012\right]$, the higher was women's motivation to contact them. For agreeableness, the correlation was positive but failed to reach significance $\left[r_{(31)}=0.151, p=0.401\right]$. As to male motivation to contact the women behind the nicknames, only openness $\left[r_{(34)}=0.294\right.$, $p=0.082]$ and neuroticism $\left[r_{(34)}=0.283, p=0.094\right]$ yielded significant results.

Our data concerning $\mathrm{H} 1$ show that ratings on people's personality simply based on those people's nicknames were valid. Still, the respective correlations were far from perfect. So we asked whether contact motivation was related to supposed personality scores rather than real scores. Hence, we correlated the contact motivation of women and men (sample 4) with the personality judgments by other women and men (sample 2 ). The more conscientious $\left[r_{(31)}=0.374, p=0.032\right]$ and the less neurotic $\left[r_{(31)}=-0.319, p=0.070\right]$ women believed the men behind the nicknames to be, the more likely were other women to be motivated to contact the men. For agreeableness, the correlation was positive but failed to reach significance $\left[r_{(31)}=0.208, p=0.246\right]$.

Furthermore, we found that the more open $\left[r_{(34)}=0.541\right.$, $p=0.001]$ and the more conscientious $\left[r_{(34)}=0.548, p=0.001\right]$ as well as the less neurotic $\left[r_{(34)}=-0.306, p=0.070\right]$ and the more narcissistic $\left[r_{(34)}=0.334, p=0.047\right]$ men believed the women behind the nicknames to be, the stronger were other men motivated to contact the women. Figure 2 presents a graphical summary of the findings for contact motivation. It is striking that women $(r=-0.321)$, in contrast to men $(r=0.283)$, try to avoid meeting people who are neurotic $(z=2.47, p=0.013)$.

Furthermore, it seemed of interest to investigate whether self-reported mating strategy of the nickname users would correlate with the contact motivation of our participants. It was found that the more long-term oriented a nickname user was, the higher was the participants' motivation to contact them $\left[r_{(60)}=0.238, p=0.063\right]$. However, the positive correlation between a long-term strategy and contact motivation was almost entirely driven by female contact motivation toward long-term oriented nickname users $\left[r_{(31)}=0.364, p=0.037\right]$, whereas male contact motivation was almost entirely uncorrelated with the female nickname users' mating strategy $\left[r_{(27)}=0.010, p=0.958\right]$. Also of interest is the finding that our judging participants were reluctant to contact persons who used relatively long pseudonyms (see Table 1). 


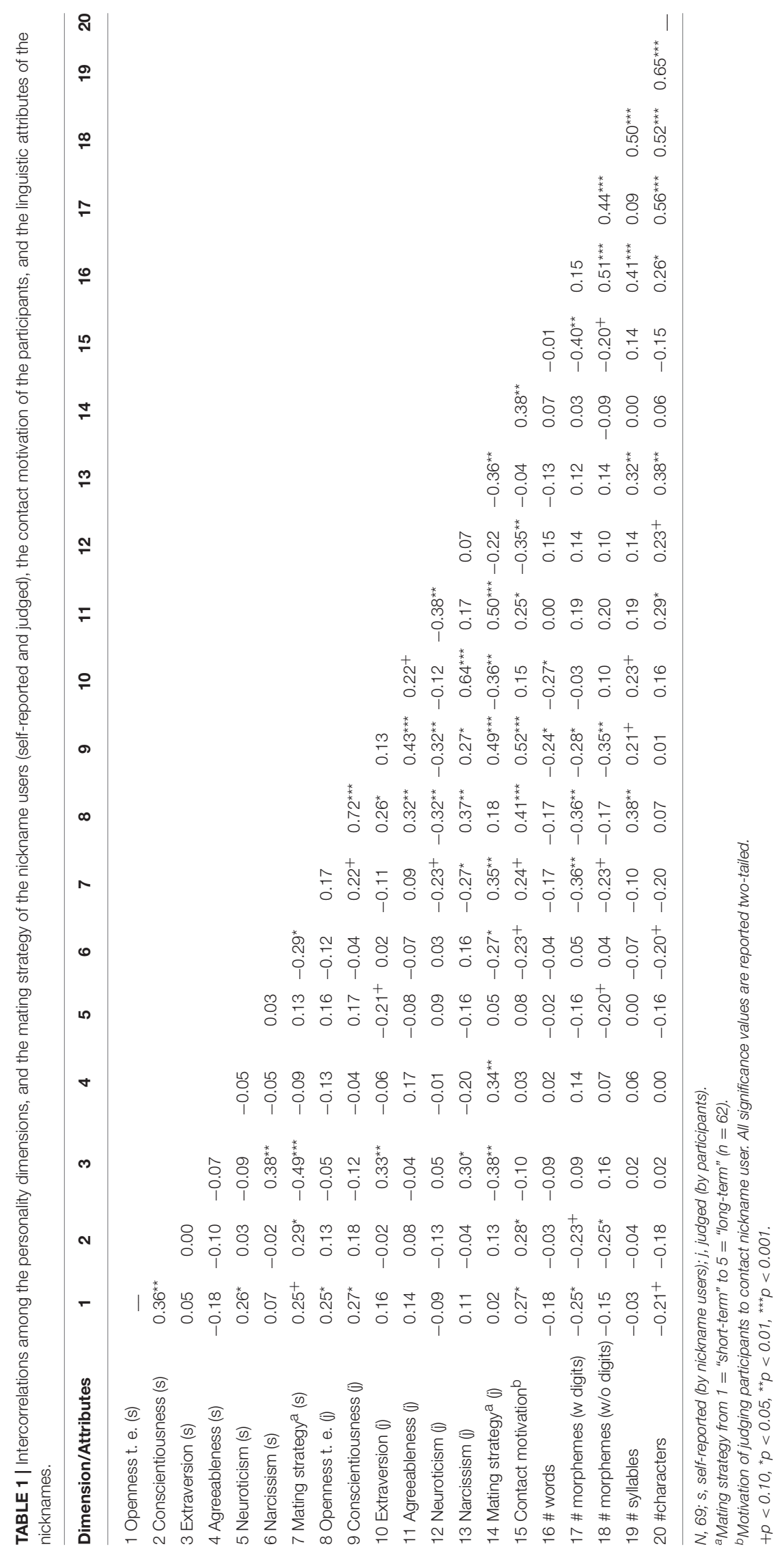



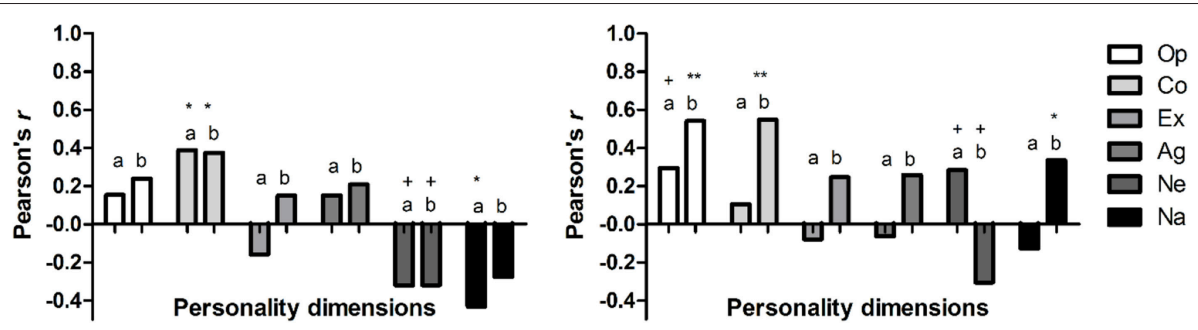

FIGURE 2 | Correlation coefficients of participants' contact motivation with (a) nickname users' self-reported personality dimensions and (b) participants' personality judgments based on nicknames: intersexual (left: women rating men, right: men rating women). Op, Openness to experience; Co, Conscientiousness; Ex,

Extraversion; Ag, Agreeableness; Ne, Neuroticism; Na, Narcissism. ${ }^{+} p<0.10,{ }^{*} p<0.05,{ }^{*} p<0.01$

\section{RQ3: Effects of Nickname Users' and Raters' Sex on Personality Judgment Accuracy}

The mean correlation coefficient for all six personality dimensions was $r_{(67)}=0.205$ for female and $r_{(67)}=0.171$ for male raters. This sex difference was not significant $(z=0.27$, $p=0.787)$. It seemed worthwhile to investigate intersexual judgments (i.e., women judging men, men judging women), as this is the actually relevant judgment here because this resembles actual mate choice. Also, intrasexual judgments (women judging women, men judging men) might be of interest (i.e., judgment of potential rivals).

First, we analyzed intersexual personality judgments. Women were on a descriptive level more accurate in judging men's personality (mean $r=0.264$ ) than men were in judging women's personality (mean $r=0.102$ ). This difference failed to reach statistical significance, though $(z=0.67, p=0.503)$. So, both women and men seem to have been able to judge correctly the personality of potential mates by means of only their nicknames ( $r s>0)$, with women being better only by trend.

Going into greater detail, we found that women could guess men's extraversion $\left[r_{(31)}=0.332, p=0.059\right]$, agreeableness $\left[r_{(31)}=0.489, p=0.004\right]$, neuroticism $\left[r_{(31)}=0.357, p=0.041\right]$, and narcissism $\left[r_{(31)}=0.349, p=0.047\right]$ correctly. Openness $\left[r_{(31)}=0.134, p=0.458\right]$ and conscientiousness $\left[r_{(31)}=-0.077\right.$, $p=0.669]$ were not detected correctly. We checked again which linguistic cues (RQ4) were used for correctly judging the personality dimensions. No significant mediation was found.

For men, we found that they were only able to correctly detect conscientiousness $\left[r_{(34)}=0.322, p=0.055\right]$ and extraversion $\left[r_{(34)}=0.287, p=0.089\right]$ in women's nicknames. Openness $\left[r_{(34)}=0.125, p=0.466\right]$, agreeableness $\left[r_{(34)}=-0.105\right.$, $p=0.541]$, neuroticism $\left[r_{(34)}=-0.031, p=0.855\right]$, and narcissism $\left[r_{(34)}=0.015, p=0.931\right]$ were thus not detected. Figure 3 gives a visual summary of the intersexual judgments.

As to the intrasexual judgments, men were, on a descriptive level, more accurate (mean $r=0.203$ ) than women (mean $r=0.134)$. However, this difference did not reach statistical significance $(z=0.28, p=0.780)$. To be precise, women were only able to detect extraversion $\left[r_{(34)}=0.318, p=0.059\right]$ in other women. Thus, for openness $\left[r_{(34)}=0.234, p=0.170\right]$, conscientiousness $\left[r_{(34)}=0.194, p=0.256\right]$, agreeableness $\left[r_{(34)}=-0.032, p=0.541\right]$, neuroticism $\left[r_{(34)}=0.085\right.$, $p=0.623]$, and narcissism $\left[r_{(34)}=0.007, p=0.966\right]$, judgments were not correct.

When analyzing the data on men judging other men, it was found that men detected extraversion $\left[r_{(31)}=0.396, p=0.022\right]$, agreeableness $\left[r_{(31)}=0.474, p=0.005\right]$, and narcissism $\left[r_{(31)}=0.301, p=0.089\right]$ correctly. For openness $\left[r_{(31)}=-0.092\right.$, $p=0.610]$, conscientiousness $\left[r_{(31)}=-0.042, p=0.818\right]$, and neuroticism $\left[r_{(31)}=0.180, p=0.317\right]$, the judgments were not valid. We checked for linguistic cues mediating the correct judgments of extraversion and agreeableness (RQ4). No significant mediation was found. Figure $\mathbf{4}$ gives a visual summary of the intrasexual personality judgments.

A visual comparison of Figures 3, 4 indicates that, by trend, women were better in intersexual judgments, while men were better in intrasexual judgments. The other side of this matechoice medal might simply be that male nicknames are more telling than female ones. Indeed, the mean correlation coefficient between self-reported and judged personality for male nicknames (with women and men as raters) was $r=0.242$, while for female nicknames (again with women and men as raters) it was only $r=0.125$. This difference, however, was not statistically significant $(z=0.48, p=0.316)$.

When investigating personality dimensions separately, we found a sex difference in intersexual as well as intrasexual judgments. Women could detect agreeableness in men remarkably well, while men were not accurate in judging agreeableness in women $(r \mathrm{~s}=0.489$ vs. $-0.105 ; z=2.54$, $p=0.011$ ). As to the intrasexual judgments, quite contrary to the intersexual judgment, men could detect agreeableness in other men, while women could not detect it in other women ( $r s=0.474$ vs. $-0.032 ; z=2.17, p=0.03$ ). Put simply, the results show that agreeableness could be inferred from male but not from female nicknames.

\section{RQ4: Linguistic Correlates of Sex Differences: Additional Analyses}

Although former research suggested male nicknames to be longer than female ones, we found no significant sex differences in this respect [all $t \mathrm{~s}_{(67)} \leq 1.309$, all $p$ s $\leq 0.191$ ]. Also, as earlier research has shown, women tend to use diminutive suffixes in their pseudonyms. In our sample, 11 out of 36 female nicknames 


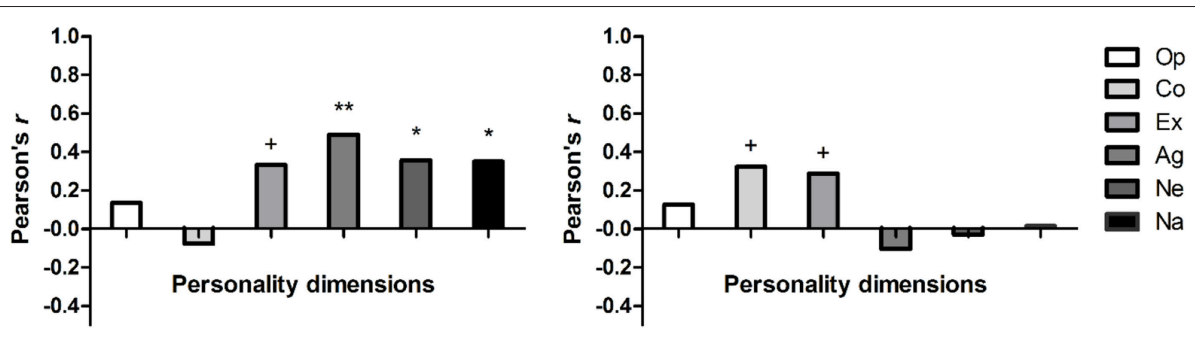

FIGURE 3 | Correlation coefficients between nickname users' self-reported personality dimensions and participants' personality judgments based on nicknames: intersexual (left: women rating men, right: men rating women). Op, Openness to experience; Co, Conscientiousness; Ex, Extraversion; Ag, Agreeableness; Ne, Neuroticism; Na, Narcissism. $+p<0.10,{ }^{\star} p<0.05,{ }^{\star \star} p<0.01$.
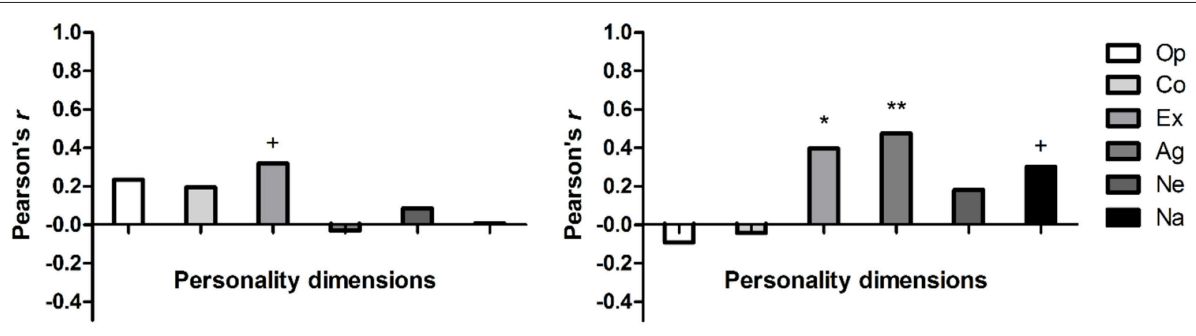

FIGURE 4 | Correlation coefficients between nickname users' self-reported personality dimensions and participants' personality judgments based on nicknames: intrasexual (left: women rating women, right: men rating men). Op, Openness to experience; Co, Conscientiousness; Ex, Extraversion; Ag, Agreeableness; Ne, Neuroticism; Na, Narcissism. $+p<0.10,{ }^{\star} p<0.05,{ }^{* \star} p<0.01$.

contained such a suffix compared to 6 out of 33 for male nicknames. This sex difference, however, was not significant $\left(\chi^{2}=1.42, p=0.23\right)$.

\section{DISCUSSION}

Research shows that many different cues can be used to make valid judgments on people's personality. Such cues include, for instance, features of someone's bedroom (Gosling et al., 2002), physical appearance (Naumann et al., 2009), or music preferences (Rentfrow and Gosling, 2006). It does not surprise that studies have also investigated cues to people's personality in the online world (for an overview see Tskhay and Rule, 2014). The concrete aspects thus studied include personal websites (Vazire and Gosling, 2004), online social networking sites (Buffardi and Campbell, 2008; Back et al., 2010; Darbyshire et al., 2016), social network site selfies (Qui et al., 2015), and tweets (Qiu et al., 2012). Online, people act in relative anonymity and some social cues available in $\mathrm{ftf}$ encounters are missing there. Hence, it is of relevance to investigate which of the available cues be employed to get a proper idea of a person's personality. We were able to replicate findings of the research by Back et al. (2008) by showing that based only on a nickname people are able to correctly judge the personality of the nickname users. Thus, nicknames contain valid information about their users, which is somewhat surprising, as a nickname constitutes only a small piece of linguistic material.
One difference between the study by Back et al. and ours is that in our study the highest correlation between self-reported and judged personality dimensions was for extraversion, whereas in the other study extraversion had the least accurate judgments. Similar to our results, other studies on personality judgments based on available cues have also found that extraversion is one of the traits that are detected particularly well (e.g., Gosling et al., 2002; Naumann et al., 2009; Tskhay and Rule, 2014). Another personality trait that was detected relatively well in our study was openness to experience. This fits quite well with the results of other personality judgment studies too. For instance, in the study by Gosling et al. (2002), in which attributes of people's rooms served as the cues, openness was the trait that was judged with the highest accuracy. The same was found by Vazire and Gosling (2004), when investigating personality judgments based on personal websites, by Rentfrow and Gosling (2006) in their study on judging personality based on music preferences, in the study by Küfner et al. (2010) on creative writing, and by Darbyshire et al. (2016) who had facebook profiles as their subject matter.

In their study on facebook profiles, Back et al. (2010) also found that extraversion and openness to experience were detectable particularly accurately. So, why are extraversion and openness detectable so well? The fact that extraversion manifests itself in the form of outgoing behavior and self-expression (McCrae and John, 1992) might already be one part of the answer. When extraversion has a strong outgoing as well as social-communicative dimension, it does not surprise that it was detected relatively well. For openness, finding an explanation is 
more difficult. Contrary to extraversion, openness is not a very interpersonal personality dimension. It rather contains features such as a sense for aesthetics and an active imagination, both of which-and this might the answer after all-might have been strongly at work when creating the nickname.

Another difference between the study by Back et al. (2008) and our study was that our participants who rated the nicknames were somewhat more accurate than those in the other study. The question arises, whether how telling a nickname is differs with the context. Back et al. (2008) looked at e-mail names in general, whereas we investigated nicknames in online dating. It might be that in a context like mate choice in which good impression management is crucial (Whitty and Buchanan, 2010), nicknames tend to contain somewhat more information than in rather unexceptional contexts. However, this poses the question why the nickname users were not communicating only "positive" traits. Is it a smart decision for an online dater to create a nickname that allows others to detect that she/he is neurotic or narcissistic? Women, though not men, were able to correctly detect these negative traits in potential mates. So the following might be true: People do not want to hide behind their nickname. And, possibly even more importantly, they cannot hide to start with-unfavorable traits shine through, too.

It was of interest to investigate which linguistic cues are used to judge the nickname users' personality. As to morphological cues, we only found one significant mediation. So, it might be that semantic cues are more revealing than morphological ones. Also, morphological cues can be misleading, as number of syllables correlated substantially both with judged openness and judged narcissism, while both self-reported openness and narcissism were uncorrelated with number of syllables (see Table 1).

Neither of the sexes was generally better than the other in correctly guessing nickname users' personality. A closer look at the data, however, revealed the tendency that women were better than men in intersexual judgments, whereas men were better than women in intrasexual judgments. Considering the wealth of research that demonstrates women to be choosier than men in mate choice decisions as well as the particularly intense intrasexual competition among men (Buss, 2003), this finding is understandable. In particular, we found that women could detect agreeableness in potential mates. Men were able to detect it in potential rivals. One explanation for this particular finding might be the following: Aggressive and abusive mates are particularly dangerous for women (see Buss, 2003). Indeed, women prefer considerate, kind, and understanding mates (Buss and Barnes, 1986), and those low in dominance as a long-term mate (Ahmetoglu and Swami, 2012). One might conclude that as the choosier sex women are good at detecting traits in a mate that might pose a risk to them. Men being the sex with a particularly intense intrasexual competition might be good in checking up on other men with respect to traits that are indicative of competition and subsequently aggression and violence.

Alternatively, one might argue that male nicknames are simply more telling than female ones. That is correct, but it leaves the question unanswered why exactly male nicknames seem to contain more information than female ones. So, female intersexual selection and male intrasexual competition remains a good explanation.

We found that mating strategy was detectable, too. This was significant for female nicknames being judged by men, but not vice versa to the same degree. This finding was surprising, as it could have been assumed that women, especially those interested in a high-quality long-term mate, should be interested in identifying men who are only looking for a fling in order to avoid these men. This very male tendency toward short-term mating might explain the finding, though. Buss and Schmitt (1993) have identified several problems that men who pursue a short-term mating strategy have to solve. One of these problems is to find women who are sexually accessible. So men have evolved adaptations that allow them to detect signs of female sexual accessibility (Buss, 2003). Considering this, it is not so surprising anymore that men were strikingly accurate in detecting women's mating strategy based on those women's nicknames.

The motivation to contact the person behind the nickname correlated, among others, with the nickname users' openness and conscientiousness. In line with this, Asendorpf et al. (2011) found that men were perceived as more attractive, the higher they scored on openness. The findings for contact motivation are in line with the hp approach, which assumes that favorable traits might be emphasized by the sender as well as idealized by the receiver.

Although more linguistic code contains more information, our judging participants were reluctant to contact persons who used relatively long nicknames. Also, long words tend to be rare and special, which is basically favorable (Lange et al., 2014). However, it could be that our participants associated nickname length with an attempt at impression management, manipulation and the like. In accordance with this, Lange et al. (2016b) found that pseudonym length was substantially correlated with the perception of the pseudonym user as showy as well as aggressive. Also, several length parameters in our study were negatively correlated both with perceived openness and perceived conscientiousness and positively with perceived narcissism. Furthermore, nickname length correlated with the pursuit of a short-term mating strategy, while most of our judging participants were probably more interested in a longterm relationship. So the reluctance to contact people using long nicknames seems plausible.

Morphological features of the nicknames in terms of their length correlated both with several of the self-reported personality dimensions as well as several related judgments. In the Back et al. (2008) study, the perception of conscientiousness was positively correlated with the number of characters. Interestingly, actual conscientiousness was almost uncorrelated with length parameters in their study. In our data, number of characters was virtually uncorrelated with perceived conscientiousness, and only in a small size correlated with actual conscientiousness. There might be a difference in the degree of creativity when choosing a nickname (as in our study) compared to choosing an e-mail name (as in the other study). While conscientious people might tend to base their e-mail name on their real names, which might turn out to be quite long, it 
might be different when choosing a nickname, where an easy choice is not as obvious as for an e-mail name.

\section{FINAL REMARKS AND CONCLUSION}

We found that personality and mating strategy could be inferred from a relatively short nickname. What was striking in our study was the sheer degree of accuracy with which the personality and the mating strategy were judged, given that these judgments were based only on a small piece of linguistic code: Numerous correlations were above 0.3 and thus, according to the effect size guideline by Gignac and Szodorai (2016), large and uncommon in social science research. However, we should be cautious when interpreting our results. We had a rather small sample and several correlations were not significant. Still, the fact that some valid personality judgments occured calls for an interpretation. First, coming back to the two approaches that we presented in our introduction that try to explain $\mathrm{cmc}$, namely rsc and hp, we found strong support against the notion that $\mathrm{cmc}$ filters out social cues-even short nicknames used in $\mathrm{cmc}$ communicate relevant social information. Second, the nicknames were used in a context that can be considered one of the most important areas of social life, namely mate choice. None of our direct ancestors remained childless. Thus, all of them must have succeeded in mate choice.

\section{REFERENCES}

Ahmetoglu, G., and Swami, V. (2012). Do women prefer "Nice Guys"? The effect of male dominance behavior on women's ratings of sexual attractiveness. Soc. Behav. Pers. 40, 667-672. doi: 10.2224/sbp.2012.40. 4.667

Asendorpf, J. B., Penke, L., and Back, M. D. (2011). From dating to mating and relating: predictors of initial and long-term outcomes of speed-dating in a community sample. Eur. J. Pers. 25, 16-30. doi: 10.1002/per.768

Back, M. D., Schmukle, S. C., and Egloff, B. (2008). How extraverted is honey.bunny77@hotmail.de? Inferring personality from e-mail addresses. J. Res. Pers. 42, 1116-1122. doi: 10.1016/j.jrp.2008.02.001

Back, M. D., Stopfer, J. M., Vazire, S., Gaddis, S., Schmukle, S. C., Egloff, B., and Gosling, S.D. (2010). Facebook profiles reflect actual personality, not self-idealisation. Psychol. Sci. 21, 372-374. doi: 10.1177/0956797609360756

Botwin, M. D., Buss, D. M., and Shackleford, T. K. (1997). Personality and mate preferences: five factors in mate selection and marital satisfaction. J. Pers. 65, 107-136. doi: 10.1111/j.1467-6494.1997.tb00531.x

Buffardi, L. E., and Campbell, W. K. (2008). Narcissism and social networking web sites. Pers. Soc. Psychol. Bull. 34, 1303-1314. doi: 10.1177/0146167208320061

Buss, D. M. (1989). Sex differences in human mate preferences: evolutionary hypotheses testing in 37 cultures. Behav. Brain Sci. 12, 1-49. doi: 10.1017/S0140525X00023992

Buss, D. M. (2003). The Evolution of Desire: Strategies of Human Mating, 2nd Edn. New York, NY: Basic Books.

Buss, D. M. (2016). Evolutionary Psychology. The New Science of the Mind. New York, NY: Routledge.

Buss, D. M., Abbott, M., Angleitner, A., Asherian, A., Biaggio, A., BlancoVillasenor, A., et al. (1990). International preferences in selecting mates: a study in 37 cultures. J. Cross Cult. Psychol. 21, 5-47. doi: 10.1177/00220221902 11001

Buss, D. M., and Barnes, M. (1986). Preferences in human mate selection. J. Pers. Soc. Psychol. 50, 559-570. doi: 10.1037/0022-3514.50.3.559

Buss, D. M., and Schmitt, D. P. (1993). Sexual strategies theory: an evolutionary perspective on human mating. Psychol. Rev. 100, 204-232. doi: 10.1037/0033-295X.100.2.204
And so do we-or at least try to. The stakes are high, and thus no one should be surprised that online dating has grown into a billion-dollar business. Where if not in a game that is close to a do-or-die competition should people give all they have to make a good first impression? And this game kicks off with the choice of a nickname.

\section{AUTHOR CONTRIBUTIONS}

BL, MvA-W, and DA contributed to the planning of the studies, the preparation of the materials, and the supervision of the data collection. BL, MvA-W, and EZ analyzed the data. BL, MvA-W, $\mathrm{DA}$, and EZ wrote the manuscript.

\section{FUNDING}

This publication was funded by the German Research Foundation (DFG) and the University of Wuerzburg in the funding programme Open Access Publishing.

\section{ACKNOWLEDGMENTS}

BL, MvA-W, DA, and EZ would like to thank LA for his contribution.

Darbyshire, D., Kirk, C., Wall, H. J., and Kaye, L.K. (2016). Don't judge a (Face)Book by its cover: Exploring judgement accuracy on other's personality on Facebook. Comput. Hum. Behav. 58, 380-387. doi: 10.1016/j.chb.2016.01.021

Eckert, P., and McConnell-Ginet, S. (2003). Language and Gender. Cambridge: Cambridge University Press. doi: 10.1017/CBO9780511791147

Ellis, L., Hershberger S., Field, E., Wersinger, S., Pellis, S., Geary, D., et al. (2008). Sex Differences. Summarizing More Than a Century of Scientific Research. Hove: Taylor \& Francis Group.

Escorial, S., and Martín-Buro, C. (2012). The role of personality and intelligence in assortative mating. Span. J. Psychol. 15, 680-687. doi: 10.5209/rev_SJOP.2012.v15.n2.38879

Finkel, E. J., Eastwick, P. W., Karney, B. R., Reis, H. T., and Sprecher, S. (2012). Online dating. A critical analysis from the perspective of psychological science. Psychol. Sci. Public Interest 13, 3-66. doi: 10.1177/1529100612436522

Gignac, G. E., and Szodorai, E. T. (2016). Effect size guidelines for individual differences researchers. Pers. Individ. Dif. 102, 74-78. doi: 10.1016/j.paid.2016.06.069

Gobrogge, K. L., Perkins, P. S., Baker, J. H., Balcer, K. D., Breedlove, S. M., and Klump, K. L. (2007). Homosexual mating preferences from an evolutionary perspective: Sexual selection theory revisited. Arch. Sex. Behav. 36, 717-723. doi: 10.1007/s10508-007-9216-x

Gosling, S. D., Ko, S. J., Mannarelli, T., and Morris, M. E. (2002). A room with a cue: personality judgments based on offices and bedrooms. J. Pers. Soc. Psychol. 82, 379-398. doi: 10.1037/0022-3514.82.3.379

Guiller, J., and Durndell, A. (2007). Students linguistic behaviour in online discussion groups: does gender matter? Comput. Hum. Behav. 23, 2240-2255. doi: 10.1016/j.chb.2006.03.004

Hayes, A. F. (2013). Introduction to Mediation, Moderation, and Conditional Process Analysis. New York, NY: The Guilford Press.

Heisler, J. M., and Crabill, S. C. (2006). Who are "stinkybug" and "Packerfan4"? Email pseudonyms and participants perceptions of demography, productivity and personality. J. Comput. Media Commun. 12, 114-135. doi: 10.1111/j.1083-6101.2006.00317.x

Koch, S. C., Mueller, B., Kruse, L., and Zumbach, J. (2005). Constructing gender in chat groups. Sex Roles 53, 29-41. doi: 10.1007/s11199-005-4276-7 
Kock, N. (2004). The psychobiological model: Towards a new theory of computermediated communication based on Darwinian evolution. Organ. Sci. 15, 327-348. doi: 10.1287/orsc. 1040.0071

Küfner, A. C. P., Back, M. D., Nestler, S., and Egloff, B. (2010). Tell me a story and I will tell you who you are! Lens model analyses of personality and creative writing. J. Res. Pers. 44, 427-435. doi: 10.1016/j.jrp.2010.05.003

Küfner, A. C. P., Dufner, M., and Back, M. D. (2015). Das Dreckige Dutzend und die Niederträchtigen Neun - Kurzskalen zur Erfassung von Narzissmus, Machiavellismus und Psychopathie. [The Dirty Dozen and the Naughty Nine-Short scales for the assessment of Narcissism, Machiavellianism and Psychopathy]. Diagnostica 61, 76-91. doi: 10.1026/0012-1924/a000124

Lange, B. P., Hennighausen, C., Brill, M., and Schwab, F. (2016a). Only cheap talk after all? New experimental psychological findings on the role of verbal proficiency in mate choice. Psychol. Lang. Commun. 20, 1-22. doi: 10.1515/plc-2016-0001

Lange, B. P., Zaretsky, E., and Euler, H. A. (2016b). Pseudo names are more than hollow words: Sex differences in the choice of pseudonyms. J. Lang. Soc. Psychol. 35, 287-304. doi: 10.1177/0261927X15587102

Lange, B. P., Zaretsky, E., Schwarz, S., and Euler, H. A. (2014). Words won't fail: experimental evidence on the role of verbal proficiency in mate choice. J. Lang. Soc. Psychol. 33, 482-499. doi: 10.1177/0261927X13515886

McCrae, R. R., and John, O. P. (1992). An introduction to the five-factor model and its applications. J. Pers. 60, 175-215. doi: 10.1111/j.1467-6494.1992.tb00970.x

Mealey, L. (2000). Sex Differences: Development and Evolutionary Strategies. San Diego, CA: Academic Press.

Naumann, L. P., Vazire, S., Rentfrow, P. J., and Gosling, S. D. (2009). Personality judgments based on physical appearance. Pers. Soc. Psychol. Bull. 35, 1661-1671. doi: 10.1177/0146167209346309

Park, G., Schwartz, H. A., Eichstaedt, J. C., Kern, M. L., Kosinski, M., Stillwell, D. J.,et al. (2015). Automatic personality assessment through social media language. J. Pers. Soc. Psychol. 108, 934-952. doi: 10.1037/pspp0000020

Perneger, T. V. (1998). What's wrong with Bonferroni adjustments. Br. Med. J. 316, 1236-1238.

Qiu, L., Lin, H., Ramsay, J., and Yang, F. (2012). You are what you tweet: Personality expression and perception on Twitter. J. Res. Pers. 46, 710-718. doi: 10.1016/j.jrp.2012.08.008

Qui, L., Lu, J., Yang, S. Qu, W., and Zhu, T. (2015). What does your selfie say about you? Comput. Hum. Behav. 52, 443-449. doi: 10.1016/j.chb.2015.06.032

Rammstedt, B., and John, O. P. (2007). Measuring personality in one minute or less: a 10-item short version of the Big Five Inventory in English and German. J. Res. Pers. 41, 203-212. doi: 10.1016/j.jrp.2006.02.001

Rentfrow, P. J., and Gosling, S. D. (2006). Message in a ballad: the role of music preferences in interpersonal perception. Psychol. Sci. 17, 236-242. doi: 10.1111/j.1467-9280.2006.01691.x

Rothman, K. J. (1990). No adjustments are needed for multiple comparisons. Epidemiology 1, 43-46. doi: 10.1097/00001648-199001000-00010

Sautter, J. M., Tippett, R. M., and Morgan, S. P. (2010). The social demography of internet dating in the United States. Soc. Sci. Q. 91, 554-575. doi: 10.1111/j.1540-6237.2010.00707.x

Savicki, V., Kelley, M., and Oesterreich, E. (1999). Judgements of gender in computer-mediated communication. Comput. Hum. Behav. 15, 185-194. doi: 10.1016/S0747-5632(99)00017-5
Schmitt, D. P. (2005). Sociosexuality from Argentina to Zimbabwe: A 48-nation study of sex, culture, and strategies of human mating. Behav. Brain Sci. 28, 247-311. doi: 10.1017/S0140525X05000051

Schwarz, S., and Hassebrauck, M. (2012). Sex and age differences in mate selection preferences. Hum. Nat. 23, 447-466. doi: 10.1007/s12110-012-9152-x

Sproull, L., and Kiesler, S. (1986). Reducing social context cues: electronic mail in organizational communication. Manage. Sci. 32, 1492-1512. doi: $10.1287 /$ mnsc.32.11.1492

Thomson, R., and Murachver, T. (2001). Predicting gender from electronic discourse. Br. J. Soc. Psychol. 40, 193-208. doi: 10.1348/014466601164812

Trivers, R. L. (1972). "Parental investment and sexual selection," in Sexual Selection and the Descent of Man, ed B. B. Campbell (Chicago, IL: Aldine), 136-179.

Tskhay, K., and Rule, N. O. (2014). Perception of personality in text-based media and OSN: a meta-analysis. J. Res. Pers. 49, 25-30. doi: 10.1016/j.jrp.2013.12.004

Valkenburg, P. M., and Peter, J. (2007). Who visits online dating sites? Exploring some characteristics of online daters. CyberPsychol. Behav. 10, 849-852. doi: $10.1089 / \mathrm{cpb} .2007 .9941$

Vander Molen, R. J., Kaplan, S., Choi, E., and Montoya, D. (2018). Judgments of the Dark Triad based on Facebook profiles. J. Res. Pers. 73, 150-163. doi: 10.1016/j.jrp.2017.11.010

Vazire, S., and Gosling, S. D. (2004). e-Perceptions: personality impressions based on personal websites. J. Pers. Soc. Psychol. 87, 123-132. doi: 10.1037/0022-3514.87.1.123

Walther, J. B. (1996). Computer-mediated communication: impersonal, interpersonal and hyperpersonal communication. Commun. Res. 23, 3-43. doi: $10.1177 / 009365096023001001$

Walther, J. B., Loh, T., and Granka, L. (2005). Let me count the ways: the interchange of verbal and nonverbal cues in computer-mediated and faceto-face affinity. J. Lang. Soc. Psychol. 24, 36-65. doi: 10.1177/0261927X042 73036

Walther, J. B., and Parks, M. R. (2002). "Cues filtered out, cues filtered in: computer-mediated communication and relationships," in Handbook of Interpersonal Communication, eds M. L. Knapp and J. A. Daly (Thousand Oaks, CA: Sage), 529-563.

Whitty, M. T., and Buchanan, T. (2010). What's in a screen name? Attractiveness of different types of screen names used by online daters. Int. J. Internet Sci. 5, 5-19.

Conflict of Interest Statement: The authors declare that the research was conducted in the absence of any commercial or financial relationships that could be construed as a potential conflict of interest.

The reviewer SS declared a past co-authorship with one of the authors BL to the handling editor.

Copyright (c) 2019 Lange, von Andrian-Werburg, Adler and Zaretsky. This is an open-access article distributed under the terms of the Creative Commons Attribution License (CC BY). The use, distribution or reproduction in other forums is permitted, provided the original author(s) and the copyright owner(s) are credited and that the original publication in this journal is cited, in accordance with accepted academic practice. No use, distribution or reproduction is permitted which does not comply with these terms. 